\title{
BIOMASS BURNING AEROSOL OVER ROMANIA USING DISPERSION MODEL AND CALIPSO DATA
}

\author{
Victor Nicolae $^{1^{*}}$, Alexandru Dandocsi ${ }^{1,2}$, Luminita Marmureanu ${ }^{1}$, Camelia Talianu ${ }^{1,3}$ \\ ${ }^{I}$ National Institute of $R \& D$ for Optoelectronics, *Email: victor.nicolae@inoe.ro \\ ${ }^{2}$ University POLITEHNICA of Bucharest, Faculty of Applied Sciences, Bucharest, Romania \\ ${ }^{3}$ Institute of Meteorology, University of Natural Resources and Life Sciences, Vienna, Austria
}

\begin{abstract}
The purpose of the study is to analyze the seasonal variability, for the hot and cold seasons, of biomass burning aerosol observed over Romania using forward dispersion calculations based on FLEXPART model. The model was set up to use as input the MODIS fire data with a degree of confidence over 25\% after transforming the emitted power in emission rate. The modelled aerosols in this setup was black carbon coated by organics. Distribution in the upper layers were compared to Calipso retrieval.
\end{abstract}

\section{INTRODUCTION}

One of the driving forces of EARTH's radiative budget is played by the aerosols particles. The origin of the particles is related with anthropogenic or natural sources, such as industry, volcanic emissions, or wild fires. Aerosols emitted by fires contain mainly two components that have different optical behavior: black carbon (BC) which absorbs solar radiation, thus having a direct positive impact on the radiative budget and second organic carbon (OC), that mainly scatter solar radiation[1]. Pollution resulted from biomass burning combined with urban pollution is due to anthropogenic activities and represents the main source of primary aerosols, having a significant impact on human health and climate[2]. Forty percent of the total emission of black carbon is related to biomass burning. Understanding the evolution, the regional distribution, and behavior of $\mathrm{BC}$ is important for climate modeling, but also for regulation related to emission control. The high uncertainty related to aerosols[1]represents a major challenge to quantify and to anticipate the effects on air quality, climate and meteorology, at local, regional and global level.

Different characteristics related with the type of vegetation, moisture, aging processes and the degree of mixing with other aerosols, have an important impact on aerosol optical properties.

In this study we analyze the biomass burning aerosols distribution over Romania using FLEXPART model, during the hot and cold season, by evaluating the output of the model when Calipso data were available.

\section{METHODOLOGY}

This study has been performed for Romania during summer 2016 and winter 2016-2017 based on the FLEXPART aerosol dispersion model (version 9.3) and MODIS Fire Radiative Power (FRP) observations. Assessment of the results using the CALIPSO satellite measurements over Romania was also performed.

\subsection{Flexpart model}

FLEXPART ("FLEXible PARTicle dispersion model") is a Lagrangian model designed for computing the long-range transport, diffusion, dry and wet deposition, and radioactive decay of air pollutants from point sources for a large number of particles (assimilated with infinitesimal small air areas)[3][4], The particle dispersion model calculations can be done assuming two ways of transport in the atmosphere: passive transport without involving removal processes and a mode assuming aerosol-like removal by dry and wet deposition. In this analysis, the contribution of the different biomass burning aerosol sources were calculated with FLEXPART forward simulations for 20000 particles based on 6-hourly Global Forecast System (GFS) real-time analysis and 1hour forecast products and with $0.5^{0} \times 0.5^{0}$ resolution [3].

To cover as much biomass burning aerosol types, we defined four anthropogenic sources based on the Selected Nomenclature for Air Pollution (SNAP): Industrial (SNAP 34, SNAP 5, SNAP6), 
Urban (SNAP 1, SNAP 2, SNAP 6), Agriculture (SNAP 10), Traffic (SNAP 7, SNAP 8).The SNAP source categories used in this study are shown in Table 1.

\section{Table 1: SNAP source categories}

\begin{tabular}{l|l} 
SNAP & Sector name \\
\hline 1 & Energy industries \\
\hline 2 & Non-Industrial combustion \\
\hline 34 & Industry (combustion and processes) \\
\hline 5 & Extraction and distribution of fossil fuels \\
\hline 6 & Product use \\
\hline 7 & Road transport \\
\hline 8 & Non-road transport and other mobile sources \\
\hline 9 & Waste treatment \\
\hline 10 & Agriculture
\end{tabular}

The biomass burning aerosol (BBA) generated for this analysis was considered as BC coated by organics, with a mono mod lognormal size distribution (accumulation mode) and the size range between $0.1 \mu \mathrm{m}-1 \mu \mathrm{m}$. The BBA composition was considered taking account of the TNO MACC III anthropogenic emission inventory for time period 2000 - 2011 [4]. We considered three species: BC, Primary organic matter (POM), and Sulphate $\left(\mathrm{SO}_{4}\right)$, which could generate the BBA defined in this study. The correlation between sources and species mass

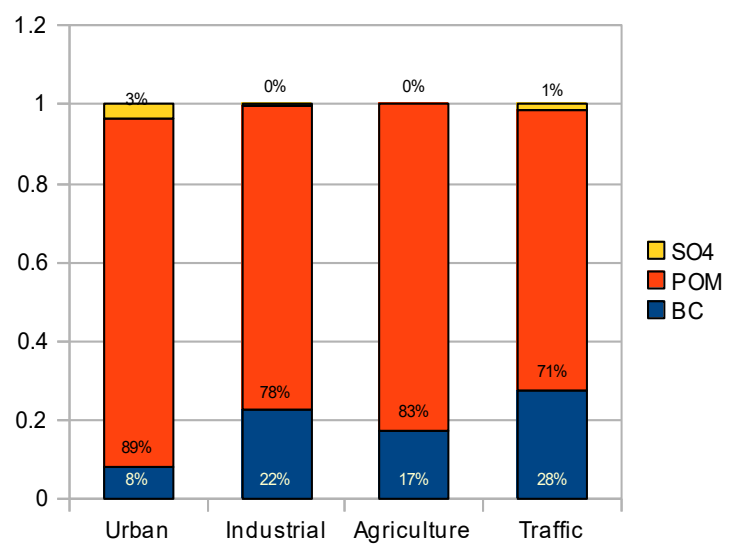

contribution to aerosols is presented in Fig. 1.

Figure 1 Biomass burning tracer generated for 4 anthropogenic sources

In the model, the species are run in forward mode without involving removal processes and tracer particles are dropped from the simulation after 3 days. This aerosol tracer was added in model with the emission algorithm using MODIS fire detections, landuse information, and emission factors.

\section{$2.2 \quad$ MODIS fire detections}

The assimilated data in the model is based on AQUA and TERRA satellite retrieval Fire Radiative Power (FRP). FRP represents a measure of radiative energy emitted per time unit in case of a fire incident. The FRP value is directly proportional to the fuel burned in the fire event. The evaluation of thermal anomalies detected by MODIS sensors are based on brightness temperature difference at $4 \mu \mathrm{m}$ [5].The concentration was retrieved from FLEXPART based on emission rate derived from FRP and emission coefficient established by Ichokuet al., 2014 [7]. The fire period was estimated for 1 day, including in the model the smouldering period.

\subsection{Calipso measurements}

The Caliop sensor from the Calipso satellite it is a depolarisation LIDAR that provide vertical profiles of high resolution of aerosols and clouds. CALIOP has 2 lasers Nd:YAG, but uses just one for every measurements. Every laser produce simultaneously pulses at 1064 and 532nm. The laser footprint at the earth surface is $70 \mathrm{~m}$ at every $333 \mathrm{~m}$. The instrument provides continuous measurements during day and night[8]. The three receptions channels of the CALIOP are focused on backscattering at $1064 \mathrm{~nm}$ and two channels that measure the polarized components of the backscatter signal at $532 \mathrm{~nm}$. Calipso data are sent once per day to the ground segment, being processed and archived. Level 2 data from Calipso were used in order to retrieve the biomass burning aerosol layers. Defining a minimum and a maximum longitude range $(20.25 \mathrm{E}, 29.68 \mathrm{E}$ respectively) and a minimum and a maximum latitude range $(43.61 \mathrm{~N}, 48.25 \mathrm{~N}$ respectively) a perimeter in the Romanian region was defined. The data selected in this perimeter have characteristics of smoke aerosols which means a lidar ratio of $70 \mathrm{sr}$ in the visible (VIS) wavelength and $40 \mathrm{sr}$ in the infrared (IR) wavelength. The Cloud - Aerosol Discrimination (CAD) score of this data had been constrained to be lower than 25 and higher than -100 . Negative values means aerosol products and the numeric value represents 
the level of confidence. We selected the days with more than 85 points in the perimeter described above, and we used the level 2 aerosol profile products from Calipso which provides profiles of backscatter coefficient, extinction coefficient, and the particle depolarization ratio from the VIS region and relative humidity profiles which were used to provide the mass concentration profiles. Using the OPAC simulation for the massextinction efficiencies and the methodology described by [9] and [10] based on:

$$
\beta_{\text {high }}^{\text {part }}=\beta_{\text {total }}^{\text {part }} \cdot \frac{\left(\delta_{\text {total }}^{\text {part }}-\delta_{d}^{\text {part }}\right)}{\left(\delta_{\text {high }}^{\text {part }}-\delta_{\text {low }}^{\text {part }}\right)} \cdot \frac{\left(1+\delta_{\text {high }}^{\text {part }}\right)}{\left(1+\delta_{\text {total }}^{\text {part }}\right)}
$$

where $\delta_{\text {total }}^{\text {part }}$ is the particle depolarization ratio and $\beta_{\text {total }}^{\text {part }}$ is the total particle backscatter coefficient.

\section{RESULTS AND DISCUSSIONS}

A comparison of observed and model-estimated BBA concentration for 2 cases during the summer 2016 is shown in Fig. 2,3 underlining the sensitivity on BBA presence also from Caliop measurements and from FLEXPART. Another two cases, when Calipso data were (01.04.2016 and 15.09.2016) available, were analyzed confirming the BBA presence (not shown).
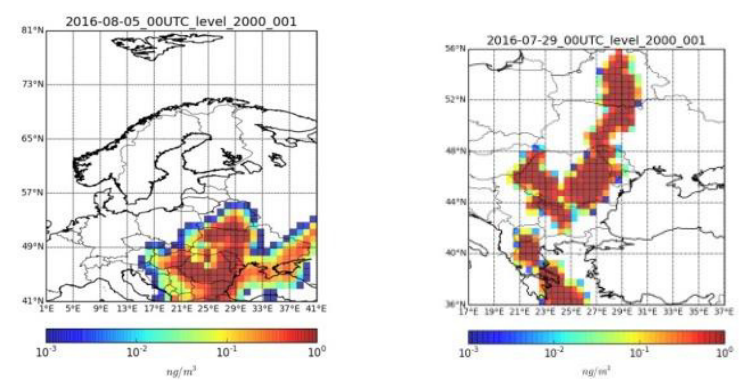

Figure 2BBA distribution over Romania on 05 August respectively 29 July 2016

A comparison profile to profile from Calipso and FLEXPART are still too early to be done due to some uncertainties related to meteorological simulations, approximations in the PBL differences between grid estimation and punctual measurement, altitude of smoke injection in to the atmosphere, time of smoldering and sub-grid effect. Previous studies demonstrate also that these limitations can influence in a significant way the comparisons at small scale. [11]

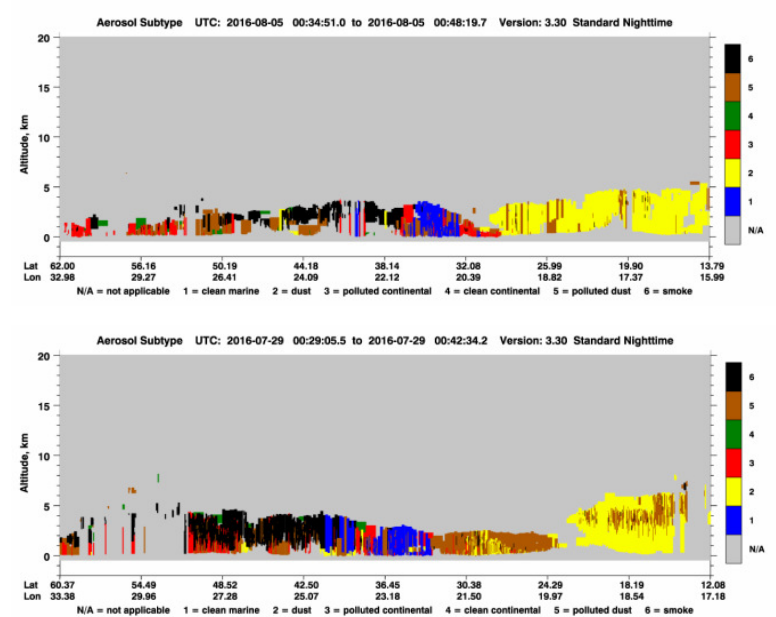

Figure 3Position (altitude, latitude and longitude) and type of the aerosol layers detected by CALIPSO for 5.08.2016, and 29.07.2016 black color indicating smoke aerosol particles.

The model used in this study is suitable tool to identify the plumes at different altitudes, affected areas by high concentrations in BBA, and to asses from the qualitatively point of view the plume evolution. In this context we analyzed the most affected areas by BBA over Romania, generating sensitivity maps (model based) on two seasons. The summer average BBA distribution (computed from first of July to end of August) over Romania show important influences from surrounding area. (Fig.4).

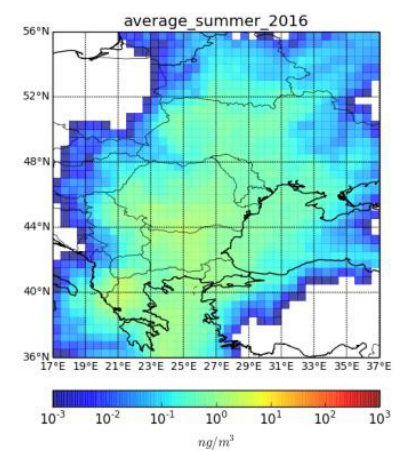

Figure 4 Average summer distribution of BBA mass concentration over Romania

The presence of vegetation fires in the South of Europe influences the aerosol concentrations over Romania, higher in the South part and lowest in center of the country, the Carpathian mountains acting as a natural barrier. 


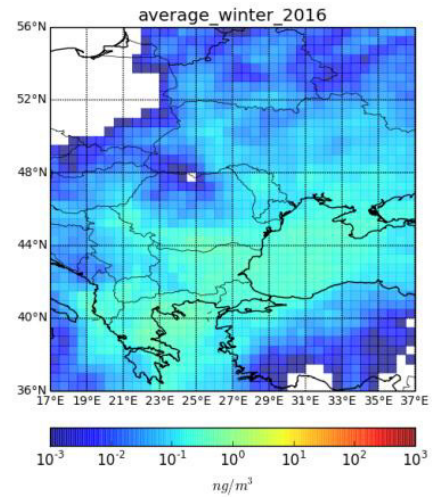

Figure 5 Average winter distribution of BBA mass concentration over Romania

During the cold season considered, from November to January, lower influences of BBA aerosol were observed over Romania (Fig.5). It must be mentioned that the data assimilated from the satellite MODIS sensors, during winter, is not taking into account the residential heating emission, that represents one of the main sources of BBA during cold season. The important uncertainties during winter are related also to the higher cloud cover during winter[12], that underestimate the thermal hot spot presence and also the BBA occurrence in to the atmosphere.

\section{CONCLUSIONS}

Seasonal variability shows a clear variability of BBA over Romania. Low concentrations of BBA produced by wild fires are recorded during winter.

From this preliminary results the model shows a clear underestimation of the BBA mass concentration especially during winter. This approach is suitable especially for the hot season when cloud cover is lower and thermal hot spot are visible from satellite.

This first comparison indicate that models correctly represent, on average, the BBA distribution, but their performance for simulating vertical profiles structure and the exact amount of BBA should be further explored.

\section{ACKNOWLEDGEMENTS}

The research leading to these results has received funding from the European Union's Horizon 2020 Research and Innovation Programme, under Grant Agreement no 692014-ECARS and from the National Core Program- PN 16400101.

\section{References}

[1] IPCC (2013), Contribution of Working Group I to the Fifth Assessment Report of the Intergovermental Panel on Climate Change in Summary for Policymakers in Climate Change edited by T. F. Stocker, D. Qin, G. K. Plattner, M. Tignor, S. Allen, J. Boschung, A. Nauels, Y. Xia, V. Bex, P. Midgley, Cambridge University Press.

[2] Bond, T. C. et al. 2013: Bounding the role of black carbon in the climate system: A scientific assessment, J. Geophys. Res., 118, 5380-5552, doi:10.1002/jgrd.50171.

[3] Saha, S., et al. 2011, updated daily. NCEP Climate Forecast System Version 2 (CFSv2) 6-hourly Products. Research Data Archive at the National Center for Atmospheric Research, Computational and Information Systems Laboratory.

[4] Stohl, A., et al., G.,2005: Technical note: The Lagrangian particle dispersion model FLEXPART version 6.2, Atmos. Chem. Phys., 5, 24612474,doi:10.5194/acp-5-2461-2005,.

[5] Kuenen J. J. P., et al. 2014, TNO-MACC_II emission inventory; a multi-year (2003-2009) consistent highresolution European emission inventory for air quality modelling, Atmos. Chem. Phys., 14, 10963-10976,

[6] Davies, D. K., et al. Fire Information for Resource Management System: Archiving and Distributing MODIS Active Fire Data, Geos. \& Remote Sens.,47, 72-79, doi:10.1109/tgrs.2008.2002076,2009.

[7] Ichoku, C., and Ellison, L., 2014: Global top-down smoke-aerosol emissions estimation using satellite fire radiative power measurements, Atmos. Chem. Phys., 14(13), 6643-6667.

[8] Winker D., et al. 2007, Initial performance assessment of CALIOP, Geophysical Res. Lett., 34, 19, L19803.

[9] Tesche, M., et al. (2011). Optical and microphysical properties of smoke over Cape Verde inferred from multiwavelengthlidar measurements. TellusB, 63, 677-694

[10] Nemuc A., et al. Assessment of aerosol's mass concentrations from measured linear particle depolarization ratio (vertically resolved) and simulations, Atmos. Meas. Tech., 6, 3243-3255, 2013, doi:10.5194/amt-6-3243-2013

[11] Foy de B., S. P. et al., Aerosol plume transport and transformation in high spectral resolution lidar measurements and WRF-Flexpart simulations during the MILAGRO Field Campaign,Atmos. Chem. Phys., 11, 3543-3563, 2011, doi:10.5194/acp-11-3543-2011

[12] National Meteorological Administration, 2008: Climate of Romania, Editura Academiei Române, Bucharest (in Romanian) 